\title{
CORRECTION OF CARDIAC DEFECTS THROUGH A RIGHT THORACOTOMY IN CHILDREN
}

\author{
Liu Ying-long, MD, Zhang Hong-jia, MD, Sun Han-shong, MD, Li Shou-jun, MD, Su Jun-wu, MD, and \\ Yu Cun-tao, MD, Beijing, China
}

Median sternotomy is the conventional approach for correction of cardiac defects, but it is invasive and often yields poor cosmetic results. ${ }^{1}$ For this reason, a right anterolateral thoracotomy is used in selected cases. The aesthetic result is preferable and acceptable to many patients. ${ }^{2,3}$ However, the indications have been limited. $^{2,4}$ We present our technique and results of correction of cardiac defects through a right lateral thoracotomy in 351 patients, emphasizing that left-sided cardiac anomalies are not contraindications for this approach.

Patients and results. From October 1994 to July 1997, 351 patients underwent heart operations through a right thoracotomy (male 183, female 168). The mean age was $3.35 \pm 1.56$ years (range 5 months to 8 years). The mean weight was $13.78 \pm 3.67 \mathrm{~kg}$ ( 6 to $26 \mathrm{~kg}$ ). The mean cardiothoracic ratio was $0.58 \pm 0.01$ (range 0.43 to 0.73 ). All patients had a definite diagnosis made by physical examination, chest radiography, and echocardiography. The types of cardiac anomalies and the procedures are listed in Table I.

The patient is placed in the lateral decubitus position with the right side elevated 60 to 80 degrees. A skin incision about 6 to $8 \mathrm{~cm}$ in length is made obliquely between the anterior and posterior axillary folds. The upper border is the third intercostal space and the lower border is the sixth. A flap of breast tissue and pectoralis muscle is dissected from the underlying chest wall and retracted cephalad, so that the chest cavity can be entered through the fourth or third intercostal space. The pericardium is opened longitudinally 1 to $2 \mathrm{~cm}$ anterior to the phrenic nerve. After placement of two concentric purse-string sutures on the ascending aorta, it is cannulated with a $12 \mathrm{~F}$ to $18 \mathrm{~F}$ right-angled cannula. The superior vena cava is cannulated through the right atrial appendage and the inferior vena cava cannula is inserted through a stab wound at the cavoatrial junc-

From the Department of Cardiovascular Surgery, Fu Wai Cardiovascular Institute and Cardiovascular Disease Hospital, Chinese Academy of Medical Sciences and Peking Union Medical College, Beijing, China.

Received for publication Dec. 11, 1997; revisions requested Feb. 25, 1998; revisions received April 3, 1998; accepted for publication April 9, 1998.

Address for reprints: Liu Ying-long, MD, Department of Cardiovascular Surgery, Director of Laboratory of Congenital Heart Disease, Cardiovascular Institute and Cardiovascular Disease Hospital, Chinese Academy of Medical Sciences and Peking Union Medical College, Beijing, China.

J Thorac Cardiovasc Surg 1998;116:359-61

Copyright () 1998 by Mosby, Inc.

0022-5223/98 $\$ 5.00+0 \quad \mathbf{1 2 / 5 4 / 9 0 8 8 4}$ tion. Cardiopulmonary bypass is established and core cooling is begun. When the body temperature reaches $24^{\circ}$ to $32^{\circ} \mathrm{C}$, the aorta is crossclamped and cold crystalloid cardioplegic solution is infused into the ascending aorta. Acceptable exposure of the intracardiac anatomy can be obtained with a standard oblique right atriotomy or a vertical right ventriculotomy incision, and the heart anomalies can be corrected in almost the same manner as with a median sternotomy. With Fallot's tetralogy and right ventricular outflow tract obstruction, two traction sutures are placed in the infundibulum in an area free of major coronary arteries, and two small cat's-paw retractors are placed on each side of the ventriculotomy so as to get good exposure of the right ventricular outflow tract and pulmonary artery (Fig. 1). After closure of the ventricular septal defect with a Dacron patch and excision of the heavy muscle bundles, the autologous pericardium or the homograft artery with a single cusp is used in widening the right ventricular outflow tract and/or the main pulmonary artery. The aortic clamp is slowly released and intracardiac air evacuated with an aortic needle vent connected to suction. Cardiopulmonary bypass is gradually discontinued and the chest is then closed in a routine fashion.

The mean aortic crossclamp time was $31.83 \pm 20.26$ minutes (range 6 to 140 minutes). The average duration of postoperative mechanical ventilation was $18.62 \pm 23.23$ hours (range 2 to 140.72 hours). The mean thoracic and pleuropericardial drainage was $105.87 \pm 81.21 \mathrm{ml}$ (range 15 to $753 \mathrm{ml}$ ). The mean postoperative hospital stay was $7.09 \pm 0.71$ days (range 7 to 17 days). There were no early or late deaths. Complications were seen in 14 patients and included temporary neurologic deficits in one, a residual shunt through a ventricular septal defect in one, delayed cardiac tamponade in one, atelectasis in eight, and paresis of the right hemidiaphragm in three.

Discussion. The right thoracotomy is an alternative to median sternotomy with more acceptable cosmetic results in the repair of some congenital heart defects. ${ }^{2-4}$ However, some anomalies are not suitable for correction by this approach. ${ }^{2,4}$ Contraindications include pulmonary stenosis, severe pulmonary hypertension, age less than 2 years, patent ductus arteriosus, and left superior vena cava. In our practice, more types of congenital heart lesions could be corrected through this approach in children. The reasons for expanding the indications are that the thoracic cavity is smaller and the elasticity of the ribs is greater in the child than in the adult. The heart could easily be retracted posteriorly, providing better visualization, especially of the pulmonary artery and right ventricular outflow tract. However, this series includes no cases of left pulmonary artery stenosis. It is necessary to perform cardiac catheterization and correct the anomalies through a 


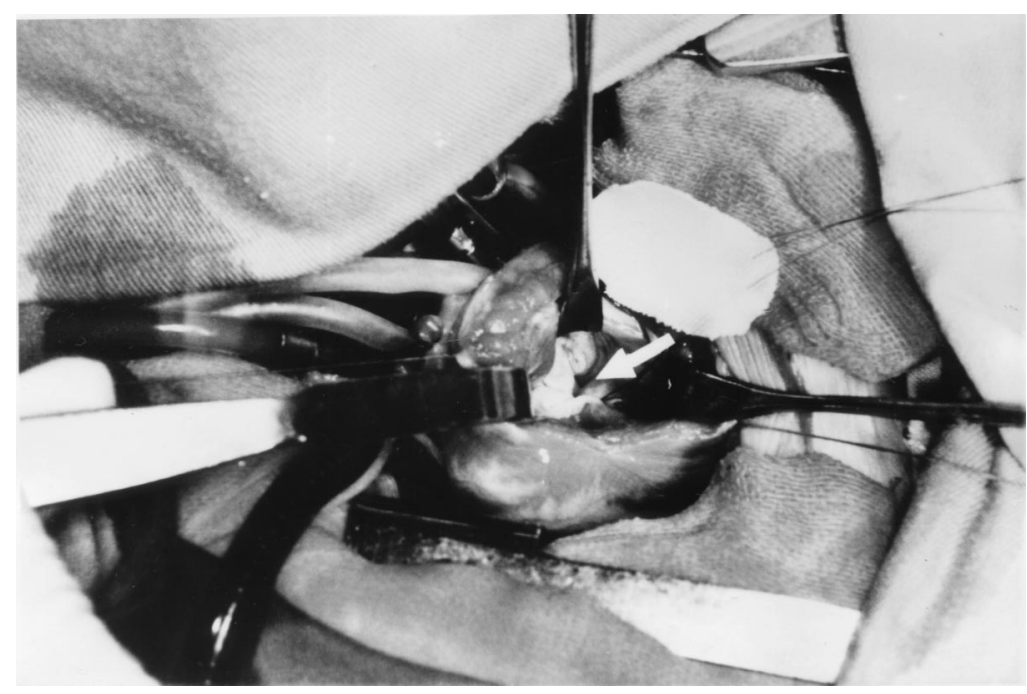

Fig. 1. Fallot's tetralogy: Operative view of a right ventriculotomy through a right lateral thoracotomy approach. Aortic cannulation is readily performed. The ventricular septal defect and the aortic valves are well exposed (arrow).

Table I. Types of cardiac anomalies and corrective procedures

\begin{tabular}{|c|c|c|c|c|c|c|c|c|c|c|c|c|}
\hline & \multirow{2}{*}{\multicolumn{2}{|c|}{ Defect repair }} & \multicolumn{3}{|c|}{ RVOTO widening } & & & & & & & \\
\hline & & & \multirow{2}{*}{$\begin{array}{c}\text { No across } \\
P V A \\
\text { Pericardium }\end{array}$} & \multicolumn{2}{|c|}{$\begin{array}{c}\text { Across } \\
\text { PVA }\end{array}$} & \multicolumn{7}{|c|}{ Correction of associated cardiac anomalies } \\
\hline & $\begin{array}{c}\text { Direct } \\
\text { closure } \dagger\end{array}$ & $\begin{array}{c}\text { Patch } \\
\text { closure } \neq\end{array}$ & & Pericardium & $\overline{H O M}$ & PDA§ & $M V P$ & $T V P$ & $P S P$ & $P A P V C$ & $S C$ I & LSVC\# \\
\hline VSD & 128 & 83 & $12 \|$ & & & 7 & 8 & 2 & & & & 3 \\
\hline ASD & 30 & 64 & & & & & & & 7 & 8 & & 2 \\
\hline TOF & & 27 & 15 & 7 & 5 & & & & & & 2 & \\
\hline PECD & & 3 & & & & & 3 & & & 1 & & 4 \\
\hline Others* & & 23 & 1 & & 1 & & 2 & & & & & \\
\hline Total & 158 & 200 & 28 & 7 & 6 & 7 & 13 & 2 & 7 & 9 & 2 & 9 \\
\hline
\end{tabular}

$V S D$, Ventricular septal defect; $A S D$, atrial septal defect; TOF, Fallot's tetralogy; $P E C D$, partial endocardial cushion defect; $P V A$, pulmonary valve anulus; $P D A$, patient ductus arteriosus; $M V P$, mitral valve prosthesis; $T V P$, tricuspid valve prosthesis; $P S P$, pulmonary stenosis prosthesis; $P A P V C$, partial anomalous pulmonary venous connection; $S C$, single coronary artery; $L S V C$, left superior vena cava; $H O M$, a patch of homograft aortic artery or pulmonary artery with single valve.

*VSD + ASD in 11 patients, mitral insufficiency in 2, and double-outflow right ventricle, double-chambered right ventricle, and left atrial myxoma, 1 each. $\dagger$ Interrupted or continuous mattress suture.

$\ddagger$ Pericardial or Dacron patch closure with continuous suture.

§Sutured from the pulmonary artery incision under the lower temperature and the lower rate of perfusion.

\|The pulmonary valve ring was excised, and the pulmonary artery and right ventricular outflow tract were widened by pericardium.

IDissected and crossclamped intermittently or cannulated through the coronary sinus.

\#VSD coexisting with right ventricular outflow tract obstruction.

median sternotomy if preoperative echocardiography suggests that the left pulmonary artery is abnormal. Much attention must be paid to suturing the patch into the right ventricular outflow tract or pulmonary artery because of difficulties in controlling hemorrhage. It is easy to deair the heart, because the left ventricular apex forms the lowest point in the field and the continuous suction on aortic vent. Of course, if the congenital heart lesion is more complex than Fallot's tetralogy or if pleural thickening or adhesions are suspected, ${ }^{5}$ a median sternotomy will be necessary. Our experience indicates that a right lateral thoracotomy can be safely performed in children for the majority of common congenital heart defects and that coexisting patent ductus arteriosus and left superior vena cava are not contraindications. In this series, the long-term follow-up ranged from 0.5 to 3 years in 326 patients. There was no impact on the development of the breast and pectoralis muscle, since the incision was between the anterior and posterior axillary folds, far from these tissues. This approach is different from the anterolateral thoracotomy, and the cosmetic results are better. It 
is consistent with the concept of minimally invasive surgery.

\section{REFERENCES}

1. Laks H, Hammond GL. A cosmetically acceptable incision for the median sternotomy. J Thorac Cardiovasc Surg 1980;79:146-9.

2. Rosengart TK, Stark JF. Repair of atrial septal defect through a right thoracotomy. Ann Thorac Surg 1993;55:1138-40.

3. Massetti M, Babatasi G, Rossi A, et al. Operation for atrial septal defect through a right anterolateral thoracotomy: current outcome. Ann Thorac Surg 1996;62:1100-3.

4. Dietl CA, Torres AR, Favaloro RG. Right submammarian thoracotomy in female patients with atrial septal defect and anomalous pulmonary venous connections. J Thorac Cardiovasc Surg 1992;104:723-7.

5. Berreklouw E, Alfieri O. Revival of right thoracotomy to approach atrioventricular valves in reoperations. Thorac Cardiovasc Surg 1984;32:331-3. 